\title{
The Fears of Being Infected by the COVID-19 Virus in Canada: A Look At Germophobes, Crowd-Averse, Fearless and Other Population Segments ${ }^{1}$
}

\author{
Fernando Mata \\ School of Sociological and Anthropological Studies, University of Ottawa, Canada, \\ E-mail: fmata@uottawa.ca \\ November 4, 2020
}

Keywords: Virus Infection Fears, Market Segmentation, COVID-19 pandemic, Canada

\begin{abstract}
The fear of being infected by the COVID-19 virus is widespread in the Canadian population. This study examined the COVID-19 virus infection fears in a survey sample of 4,200 adult Canadians aged 15 years old and over during the confinement period of June 21-26, 2020 and collected by Statistics Canada. A marketing segmentation analysis was carried out using a roster of 13 perceived health risks items leading to the identification of typical fears and the profiling of five major segments present in the Canadian adult population: "Germophobes" (7\%), "Crowd-Averse" (34\%), "Fearless" (17\%), "Outside "Bubble"-Averse" (18\%), and ""Nursing Homes-Averse" (24\%). Health risk items included a wide range of preoccupations such as visiting retirement homes, travelling by car or airplane, attending public events, shopping, eating out, seeing doctors and/or participating in sports or gyms. The five population segments were identified using a combination of principal component and $\mathrm{k}$-means cluster statistical analysis. Marketing segmentation is a useful tool for decision makers to categorize population members and, by doing so, facilitate better public campaigns, help design messages, and implement changes that can promote more efficient ways to deal with the various societal consequences of the COVID-19 confinement.
\end{abstract}

The segment mottos for the five segments can be summarized as follows: "Germs are Everywhere"; "Too Many People!", "Infections are over-rated!" "I am sticking to my bubble! and "Will not visit grandma today!". Regardless of place, circumstance and/or activity, the Germophobes were extremely fearful of contracting the virus while members of the Fearless segment, a polar opposite, underestimated health risks and carried on with their lives with minor preoccupations. Crowd-Averse, Outside "Bubble"-Averse and Nursing Homes-Averse segment members showed differences in terms of the foci of COVID-19 for potential infections such as in crowds, nursing home visitations and/or other activities such as taking care of individuals outside the household "bubble". Given their unique perceptual profiles, public health messages will be more efficient if their messages pay special attention to the particular socio-demographic, residential, employment and psychosocial characteristics of segment members.

\footnotetext{
I Paper to be presented at the 2021 CSA Meetings, Edmonton-Alberta.The author would like to thank Stein Monteiro, Jennifer Dumoulin, the Ontario Data Documentation, Extraction Service and Infrastructure (ODESIScholars Portal Statistics) as well as Statistics Canada for making available the data and valuable support and guidance.
} 


\subsection{Background}

The COVID-19 virus has caused major disruptions across the world, after being declared as a pandemic by the World Health Organization (WHO) on 31 January 2020 (WHO, 2020). This pandemic has led to a break with ordinary routine activities and social contacts for most of the world's population. Canada is presently undergoing the so-called "second" phase. As of 25 October 2020, there had been a total of 9,946 deaths attributed to the coronavirus in Canada $^{2}$. A larger number is expected in the coming months. Most of the reported cases are in Canada's two most populous provinces, Ontario and Quebec, which have declared different sanitary measures and confinement restrictions to deal with virus spread in the population.

The fear of being infected by the COVID-19 virus is widespread in the Canadian population. Fear is an important adaptive response to survival and is considered a major component of anxiety (Maeng \& Milad, 2015, Manderson and Levine, 2020). In the new environment, participation in large gatherings, nursing home visitations and airplane travel are seen by many as "risky" types of behaviour. Some people are afraid of being infected in public places such as shopping malls, gyms, bars, restaurants and/or public transport. Others are more concerned about being infected at home. Altruistic fear (fear that other family members may be infected) is different in nature from ego-oriented fear or concern for one's own well-being (Alfaroy et. al, 2020). Health risk related perceptions are key in predicting desirable health outcomes for the general population such as following sanitary guidelines emphasizing hand washing, wearing masks and keeping social distance.

Market segments are groups of individuals who are similar in their reaction to one or more mix of environmental elements (Grover and Briens, 2006). Communalities in terms of perceived health-related fears define various possible market segments which can be targeted by public health campaigns aimed at promoting social well-being and a giving a sense of security to the general population. Using a sample of the adult population of Canada, the central objectives of the marketing segmentation analysis presented here is to break down the population into meaningful clusters of individuals (homogeneous) in terms of their perceptual traits during the COVID-19 pandemic. Three central questions guided the segmentation analysis: 1) What COVID-19 virus infection fears are the most commonly reported by Canadians during the pandemic? 2) Can groups of individuals be differentiated into attitudinal segments or clusters according to their types of fears? and 3) What are the typical socio-demographic, residential, employment and other psychosocial characteristics of the members of these segments?. The CPSS-Series3 survey conducted by Statistics Canada was regarded as an ideal data source chosen to empirically explore these three central research questions and produce a statistical portrait of infection fears during the pandemic ${ }^{3}$.

\footnotetext{
2 Source: https://www.statista.com/statistics/1107079/covid19-deaths-by-province-territory-canada.

3 This study is the second market segmentation study carried out using CPSS data. The first one, focusing on routine activities which used CPSS-Series2 data, is available at: https://osf.io/preprints/socarxiv/6vumh/
} 


\subsection{Sample and Measures}

The CPSS-Series 3 survey (CPSS Series3) entitled "Resuming Economic and Social Activities" is a voluntary online survey that collected information on the knowledge and behaviours of approximately 4,200 Canadians aged 15 years old and over who were residents of the 10 Canadian provinces. It was administered by Statistics Canada between June 15-21, 2020 (the reference week). The probability panel of the CPSS-Series 3 was created by randomly selecting a subset of the Labour Force Survey (LFS) respondents. The LFS collected a wide range of information on commuting to work, economic recovery, family and caregiving, health risks and preparedness in society and community ${ }^{4}$.

A total of 13 infection risk scales were used for this analysis. These tapped into COVID19 perceived health concerns attached to various places and social activities after the resumption of activities during the first wave of the pandemic. Scales were measured as four point scores $(1=$ not at all concerned, $2=$ somewhat concerned, $3=$ very concerned and 4=extremely concerned) which were treated as indicators of low, moderate, high and very high infection risks respectively. The following general question was asked in the survey: How concerned are you about the health risks of resuming the following activities (list of 13 activities provided) as the COVID-19 safety measures are relaxed?. The list of infection risk items ranked by their average scale scores is presented in table 1. Visiting retirement homes and travelling by airplane topped the chart of the "riskiest" types of activities.

\subsection{Statistical Methods and Segment Identification}

Principal Component Analysis (PCA) and k-means cluster analysis were used as the main statistical techniques for segment identification (see detail of the methodologies followed in Punj and Stewart (1983), Grover and Vriens (2006) and Salkind and Rasmussen (2010)). In the first phase, Principal Components (statistical technique aimed at data reduction) extracted 4 major dimensions underlying information contained in the 13 scales of health risk related items. In the second phase, using component scores of these dimensions capturing about half of the total data variation $(62 \%), \mathrm{k}$-means clustering analysis was applied to the CPSS-Series data. This clustering algorithm was developed to sort survey respondents into a $\mathrm{k}$ number of clusters through assignments and re-assignments based on the shortest distance between the individual and the centroid (mass centre) of the cluster. The distance measure chosen for this purpose was the Euclidean distance squared. For the cluster analysis $k=2$ to $k=8$ segment solutions were tested. The $\mathrm{k}=6$ solution proved to be the most valid and informative according to the parsimonious reduction of the Within Sum of Squares (WSS) and the application of the "elbow" criteria as a stopping rule in the partition of clusters (see technical appendix chart A1).

\footnotetext{
4 Statistics Canada has already released major findings of the CPSS-Series 1, Series 2 and CPSS-3 surveys (conducted between March 29-April 3, 2020 and June 15-21, 2020 respectively), which include: greater anxieties over personal health and the health of others, that most Canadians were following health guidelines, greater time spent on the internet and watching television, women were stricter in terms of following guidelines than men, and youth were less likely to wear masks in public. Sources : 1) https://www150.statcan.gc.ca/n1/daily-quotidien/200408/dq200408c-eng.htm; 2) https://www150.statcan.gc.ca/n1/daily-quotidien/200708/dq200708a-eng.htm.
} 
4

The validation of the partition of the population into six clusters was verified using Analysis of Variance (ANOVA) F tests where the cluster membership was used in the prediction of the socio-demographic and attitudinal characteristics of respondents (see table A-2 in the technical appendix). The highest predicted power of the cluster partition was found in reference to the immigrant status of individuals $6 \%$ of variance explained of this particular trait).

Table 1: Average Score of Infection Risk Scales of COVID-19 ranked by their greater level of perceived risk, Canadian Adults, 2020

\begin{tabular}{|r|l|r|r|}
\hline $\begin{array}{c}\text { Item } \\
\text { Number }\end{array}$ & \multicolumn{1}{|c|}{ Infection Risk Scales (1-4 points) } & $\begin{array}{c}\text { Mean of } \\
\text { Scale } \\
\text { Score }\end{array}$ & $\begin{array}{c}\text { Std. } \\
\text { Deviation }\end{array}$ \\
\hline 1 & Visiting a retirement home & 2.97 & 0.90 \\
2 & Travelling by airplane & 2.73 & 0.71 \\
3 & Participating in sports, going to the gym & 2.69 & 0.98 \\
4 & Attending shows, festivals, movies and sport events & 2.67 & 0.70 \\
5 & Gathering in larger groups & 2.54 & 0.71 \\
6 & Taking care of people not living with respondent & 2.50 & 1.10 \\
7 & Going to restaurants or bars & 2.35 & 0.74 \\
8 & Appointments for hairdresser, esthetician, manicurist & 2.14 & 0.90 \\
9 & Shopping in stores or at the mall & 2.12 & 0.63 \\
10 & Going to the doctor or hospital & 2.06 & 0.71 \\
11 & Appointments for personal care services & 1.98 & 0.74 \\
12 & Gathering in small groups & 1.76 & 0.70 \\
13 & Travelling using your own car & 1.35 & 0.80 \\
\hline
\end{tabular}

Source: CPSS-Series3 Survey, Statistics Canada, 2020

\subsection{Findings}

\subsection{Segment Prevalence and Traits}

According to the cluster analysis of the CPSS-Series 2 data, five uniquely profiled groups of the Canadian adult population respondents were identified. Their membership was distributed as follows: $7 \%$ in segment $1,34 \%$ in segment $2,17 \%$ in segment $3,18 \%$ in segment 4 and $24 \%$ in segment 5 . Based on the typical activity profiles drawn from the 26 dichotomous scales, the segments were labeled as follows: Segment 1 - "Germophobes", Segment 2-"Crowd-Averse", Segment 3-"Fearless", Segment 4-"Outside Bubble Averse", Segment 5-"Nursing Homes-Averse" . The prevalence $\mathbf{5}$ (adult population \% share) of these segments is presented in pie chart 1.

5 Population estimates were obtained using weighted frequencies. 
Chart 1: Segment Prevalence in the Canadian adult population during the COVID-19 Pandemic, Virus Infection Fears, Canadians aged 15 years old and over

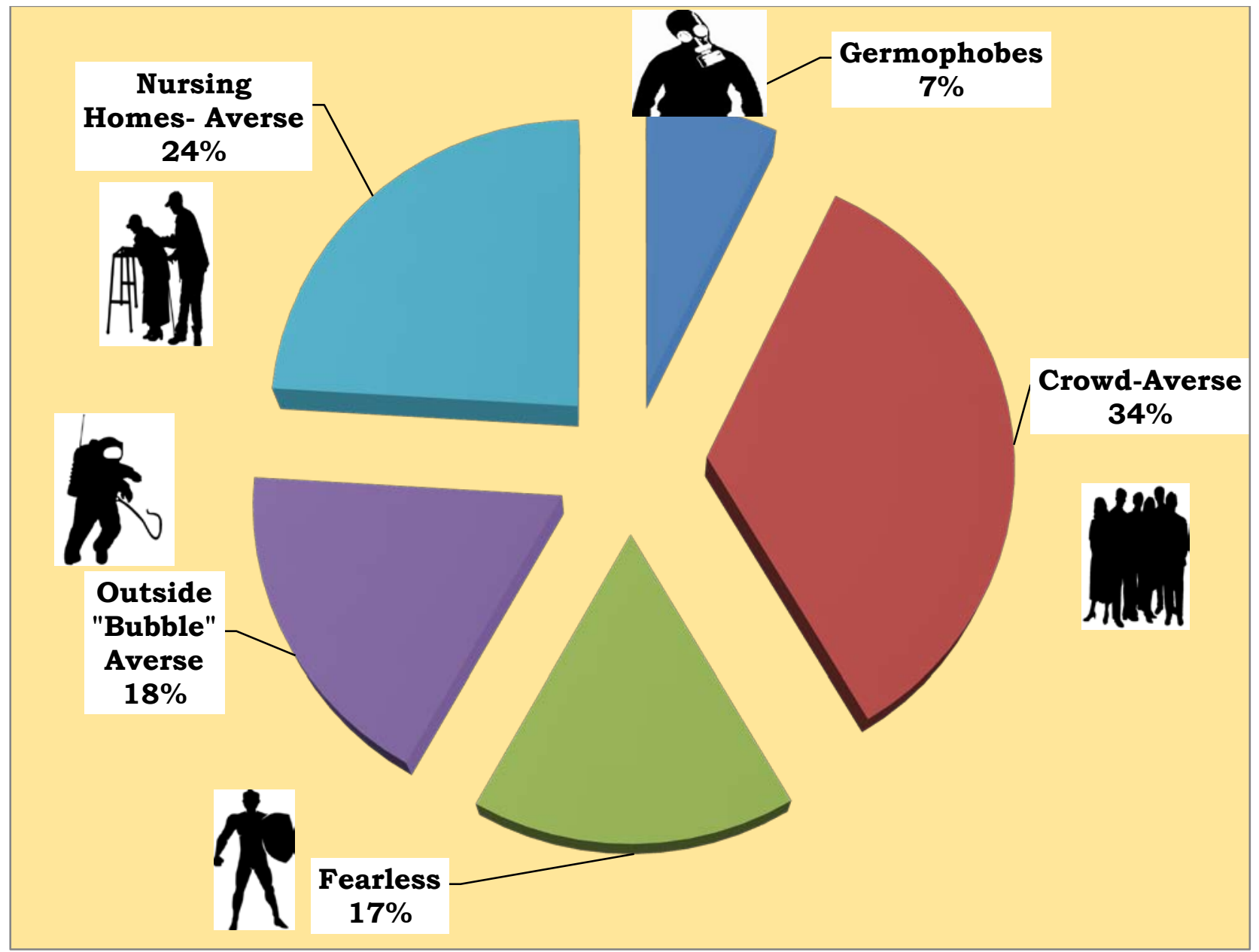

Source: CPSS-Series3 Survey, Statistics Canada, 2020

A visual representation (PCA bi-plot) of the vector of activities and dimensions underlying the data are displayed in chart 2. The first two components extracted by PCA accounted for $43.6 \%$ of the variance of all activity items. The first dimension represented by C $1(31.9 \%$ of the total variance of items) opposed as polar cases Fearless vs. the Rest of segments in terms a lesser or higher degree of fear regardless of places or activities. The second dimension, represented by $\mathrm{C} 2$ (11.6\% of the total variance of items), opposed the CrowdAverse and the Outside "Bubble"-Averse members as opposites. This opposition reveals a dimension related to the amplitude of fear from less distant to more distant or with regards to more impersonal members of society. The position of the Nursing Home-Averse segment in the bi-plot suggests that visitations to these places were the most ominous in 
6

terms of virus contagion for Canadians at this particular juncture of the pandemic.

Statistical Note: In the Chart 2 PCA bi-plot ${ }^{6}$, the first two principal components extracted from the data ( $\mathrm{C} 1$ and $\mathrm{C} 2)$ are shown. They are the most fundamental dimensions

summarizing the activity patterns reported by respondents. In the biplot, vectors represent items which are presented as points in space. The bi-plot of the second component on the first component is useful as it displays the correlations of variables in terms of various item vectors of different magnitudes, directions and positions. Proximity of activity traits to group positions in space suggests an over-representation of these traits with respect to the composition of groups while greater distances suggests its converse. Correlations between two indicator variables in component space are equal to the cosines of the angles between the indicator vectors $(\theta)$, or $r=\cos (\theta)$. Highly correlated variables are located at sharp angles from each other $(\theta=90$ degrees or less) while those zero correlated are "orthogonal" to each other $(\theta=90$ degrees). If variables are perfectly negatively correlated, then $\theta=360$ degrees (vector in opposite direction).

6 PCA biplots were obtained using XLStat as statistical software. 
Chart 2: Biplot of Virus Infection Fears Items and Population Segment Positions during the COVID-19 Pandemic, Canadians aged 15 years old and over

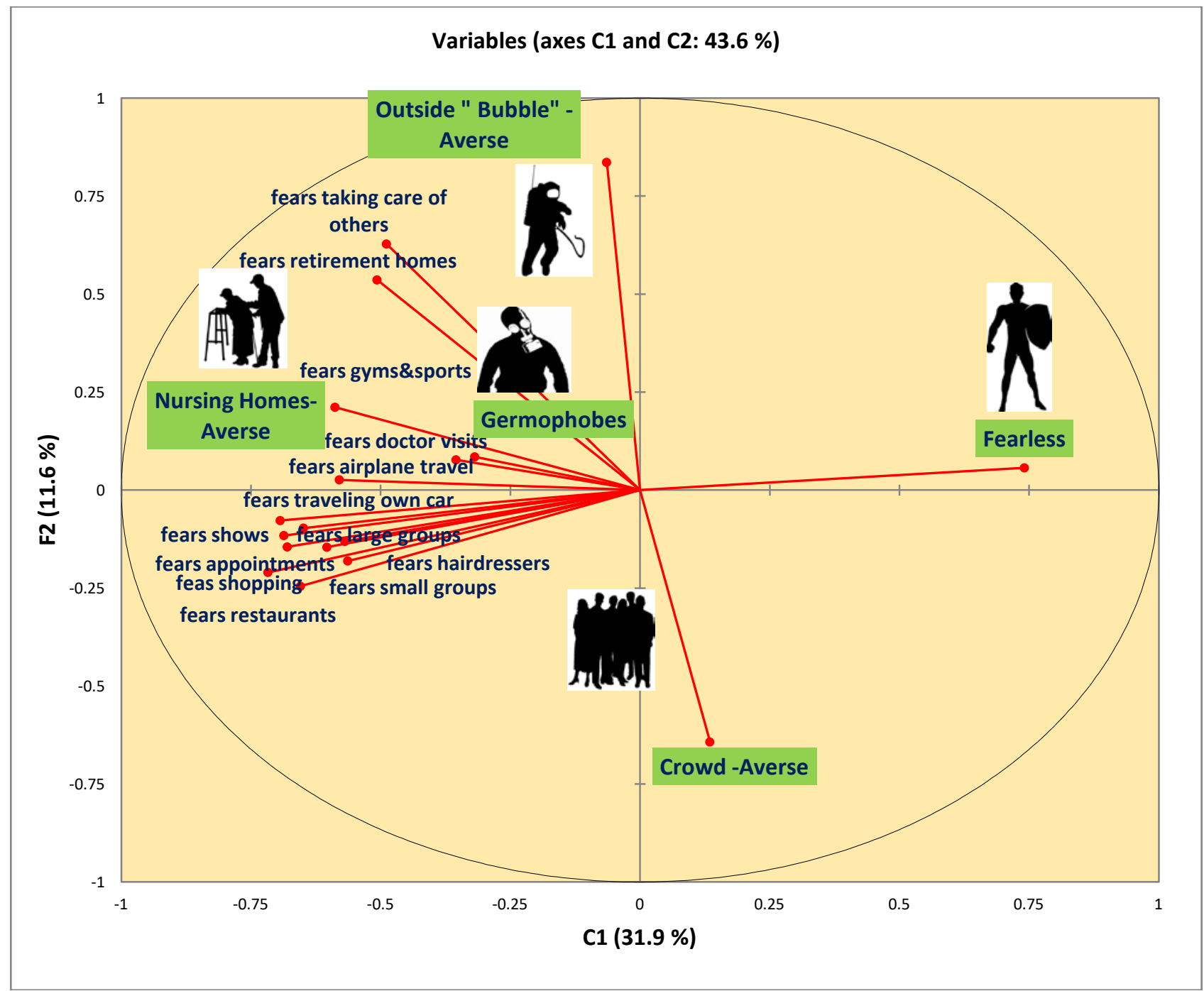

Source: CPSS-Series3 Survey, Statistics Canada, 2020 


\subsection{Segment Profile Summaries: Who Are they?}

The following are the summary descriptions of the population segments found in the CPSS-Series3 data:

\section{Segment 1 - Germophobes (7\% representing 2.3 million adult Canadians), Segment Motto: "Germs are Everywhere!"}

Members of this small population segment are very afraid and anxious about being infected by the COVID-19 virus. They perceive all types of places and social occasions as scenarios for potential contamination. Less than one in ten adult Canadians are part of this cluster of individuals. They displayed the highest cumulative scores of all 13 infection risk scales. The highest scale scores for them were those referring to travelling in their own cars (3.77 score points average), visiting nursing homes (3.32 score points average) and travelling by plane (3.29 score points average). Over-representation of females (55\%), immigrants (44\%) and individuals living in apartment buildings (46\%) are observable across segment members. The Germophobes are the least educated segment of the five segments: almost half of the members of the group had an equivalent of high school or below education (48\%). One in five (20\%) reported low levels of life satisfaction at the time of the CPSS Series 3 survey.

\section{Segment 2 - Crowd-Averse (34\% representing 10.7 Million adult Canadians), Segment Motto: "Too Many People!"}

Crowd-Averse individuals represent about one third of the adult population of Canada. Members of this segment are fear-specific oriented and react to the pandemic environment by avoiding any possible contact with crowds and gatherings in public places. They are particularly anxious with respect to attending shows $(2.76$ score points average ), dining out (2.38 score points average) and/or participating in sport activities and exercising in gyms (2.48 score points average ). About a third of the Crowd-Averse $(34 \%)$ were 35 years old or younger, 61\% were married and/or living in common-law marital status and $41 \%$ had a level education equivalent to high school diploma or less. About $12 \%$ of Crowd-Averse individuals reported low levels of life satisfaction at the time of the survey.

\section{Segment 3 - Fearless (17\% representing 5.1 million adult Canadians), Segment Motto:"Infections Are Over-Rated!"}

Members of this population segment acknowledge possibilities of contracting the COVID19 virus but believe these are somewhat remote as feel secure in not contracting any virus. They are not particularly anxious about a particular place and/or social occasion. In contrast to all the other segments, Fearless segment members displayed the lowest cumulative scores of all 13 infection risk scales (i.e.12 fear scale averages below an average score of 2 points). Males are over-represented in this segment (59\% to $49 \%$ overall) as well as rural area residents (23\% to $16 \%$ overall). About $44 \%$ of segment members were 35 years old or younger and also $43 \%$ were living with a child 18 years or old in the household. In terms of employment status, $62 \%$ were employed at work during the reference week. Only $11 \%$ of segment members reported lower levels of life satisfaction at the time of the survey. 


\section{Segment 4 - Outside "Bubble"-Averse (18\% representing 5.6 million adult Canadians), Segment Motto: "I Am Sticking to My Bubble!"}

Members of this older segment are mostly worried about being infected in places and/or social occasions taking place outside their respective household "bubbles". A "bubble" is an unofficial term used in Canada to describe people with whom the individual feels comfortable spending time during the pandemic (e.g. the household). Like members of population segments 2 and 5, Outside "Bubble"-Averse individuals experience anxiety over virus contagion, particularly in regard to the issue of providing care of individuals living outside the household (3.61 score points average ). Visit to retirement homes is also another important source of reported anxiety. Two third of segment members (66\%) were married and/or lived with a common-law partner while $44 \%$ reported home as their main work location. The Outside "Bubble"-Averse constitute the most educated population segment: about a third of them (34\%) had a diploma equivalent to a university bachelor's degree or above. One in ten of them (10\%) reported low levels of life satisfaction at the time of the survey

\section{Segment 5 - Nursing Homes-Averse (24\% representing 7.5 Adult Canadians), Segment Motto: "I Will Not Visit Grandma Today!"}

At the time of the survey, one in four Canadians can be described as Nursing HomesAverse type of individuals ${ }^{7}$. Although generally anxious about COVID-19 virus infections in various places or social situations like members of segments 1, 2 and 4, they are particularly worried about visiting family and/or relatives residing in nursing homes (3.37 score points average ). Despite their altruistic motivations, these activities are seen as highly "risky" for this population segment ${ }^{8}$. . Members of the Nursing Homes-Averse segment were almost equally divided in terms of gender and more than two-thirds $(69 \%)$ were married or living with a common law partner $(69 \%)$. About $44 \%$ reported home as their work location while $16 \%$ of them displayed a low level of life satisfaction.

\footnotetext{
7 At the time of the survey, Ontario and other provinces were tackling outbreaks in nursing homes and attempting to reopen visitations. Also, the Canadian army was called to assist nursing home residents, see: https:/ / www.theglobeandmail.com/canada/article-ontario-to-allow-family-visits-to-nursing-homes-that-arefree-of-covid/

$8^{\circ}$ Given the time persistence of virus outbreaks in nursing homes, it is expected that this population segment will be observable during the various phases of the pandemic in Canada.
} 
10

Table 2: Infection Risks Scales (Average Score) Reported by the Five Population Segments, Canada 2020

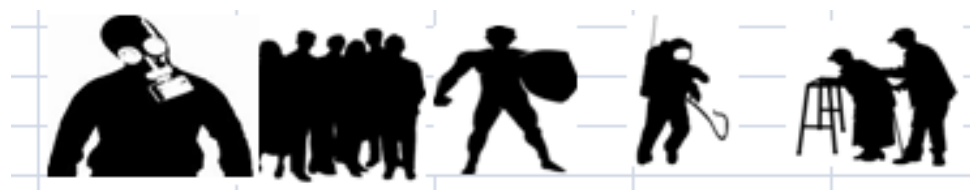

\begin{tabular}{|c|c|c|c|c|c|c|}
\hline Infection Risk Scales & 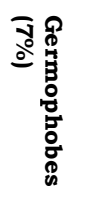 & 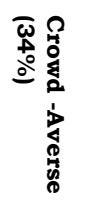 & 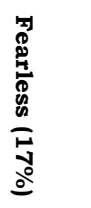 & 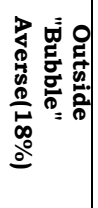 & 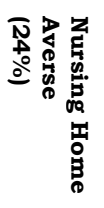 & 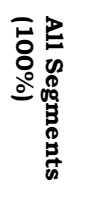 \\
\hline 1. Visiting a retirement home & 3.32 & 2.57 & 2.22 & 3.75 & 3.37 & 2.97 \\
\hline 2. Travelling by airplane & 3.29 & 2.72 & 1.94 & 2.88 & 3.02 & 2.73 \\
\hline 3. Participating in sports, going to the gym & 3.31 & 2.48 & 1.68 & 3.04 & 3.24 & 2.69 \\
\hline 4. Attending shows, festivals, movies, sports & 3.07 & 2.76 & 1.72 & 2.73 & 3.05 & 2.67 \\
\hline 5. Gathering in larger groups & 2.91 & 2.59 & 1.61 & 2.58 & 2.98 & 2.54 \\
\hline 6. Taking care of people not living with you & 3.19 & 1.90 & 1.69 & 3.61 & 2.90 & 2.50 \\
\hline 7. Going to restaurants, bars & 2.96 & 2.38 & 1.47 & 2.20 & 2.84 & 2.35 \\
\hline 8. Appointments for hairdresser, esthetician, manicurist & 2.69 & 1.99 & 1.26 & 1.96 & 2.95 & 2.14 \\
\hline 9. Shopping in stores or at the mall & 2.48 & 2.16 & 1.42 & 1.99 & 2.55 & 2.12 \\
\hline 10. Going to the doctor or hospital & 2.39 & 1.98 & 1.45 & 1.93 & 2.61 & 2.06 \\
\hline 11. Appointments for personal care services & 2.54 & 1.85 & 1.21 & 1.82 & 2.67 & 1.98 \\
\hline 12. Gathering in small groups & 2.42 & 1.71 & 1.07 & 1.61 & 2.22 & 1.76 \\
\hline 13. Travelling using your own car & 3.77 & 1.13 & 1.11 & 1.14 & 1.29 & 1.35 \\
\hline
\end{tabular}

Source: CPSS-Series3 Survey, Statistics Canada, 2020 
11

Table 3: Socio-demographic, Residential, Employment and Life Satisfaction Profiles of the Five Population Segments, Canada 2020

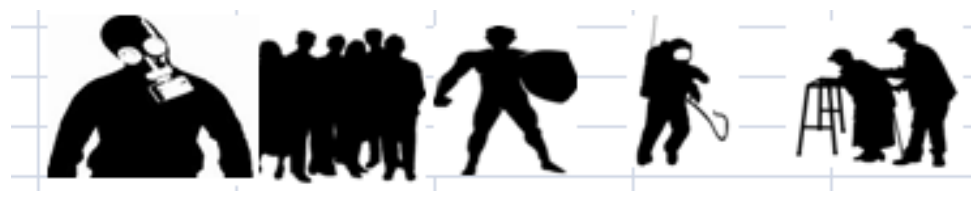

\begin{tabular}{|c|c|c|c|c|c|c|}
\hline $\begin{array}{l}\text { Socio-Demographic, } \\
\text { Residential, } \\
\text { Employment and Life } \\
\text { Satisfaction Profiles }\end{array}$ & 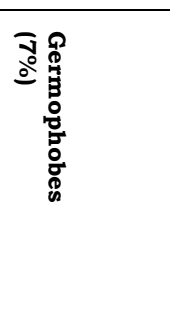 & 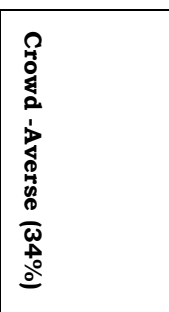 & 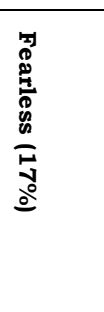 & 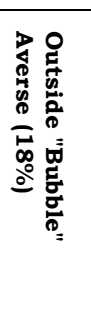 & 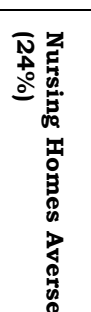 & 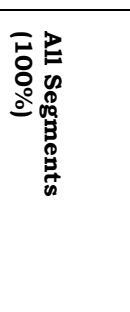 \\
\hline$\% 35$ years old or under & $29 \%$ & $34 \%$ & $44 \%$ & $22 \%$ & $25 \%$ & $31 \%$ \\
\hline$\% 65+$ years old & $29 \%$ & $19 \%$ & $\mathbf{9 \%}$ & $29 \%$ & $24 \%$ & $21 \%$ \\
\hline$\%$ Female & $\mathbf{5 5 \%}$ & $52 \%$ & $41 \%$ & $53 \%$ & $52 \%$ & $51 \%$ \\
\hline \% Married or Common Law & $41 \%$ & $61 \%$ & $53 \%$ & $66 \%$ & $69 \%$ & $61 \%$ \\
\hline$\%$ Single marital status & $39 \%$ & $28 \%$ & $38 \%$ & $21 \%$ & $20 \%$ & $27 \%$ \\
\hline \% Foreign-born & $46 \%$ & $21 \%$ & $10 \%$ & $21 \%$ & $37 \%$ & $25 \%$ \\
\hline $\begin{array}{l}\text { \% Living in households with } \\
\text { a child } 18 \text { years old or under }\end{array}$ & $32 \%$ & $34 \%$ & $43 \%$ & $26 \%$ & $33 \%$ & $34 \%$ \\
\hline $\begin{array}{l}\text { \% High School Diploma or } \\
\text { less }\end{array}$ & $48 \%$ & $41 \%$ & $42 \%$ & $32 \%$ & $38 \%$ & $39 \%$ \\
\hline $\begin{array}{l}\text { \% University education } \\
\text { equivalent to bachelor or } \\
\text { more }\end{array}$ & $26 \%$ & $27 \%$ & $23 \%$ & $34 \%$ & $29 \%$ & $28 \%$ \\
\hline$\%$ Urban residence & $93 \%$ & $83 \%$ & $77 \%$ & $82 \%$ & $89 \%$ & $84 \%$ \\
\hline $\begin{array}{l}\% \text { Living in apartment } \\
\text { building }\end{array}$ & $46 \%$ & $17 \%$ & $13 \%$ & $23 \%$ & $22 \%$ & $21 \%$ \\
\hline $\begin{array}{l}\text { \% Employed at work for at } \\
\text { least part of the reference } \\
\text { week }\end{array}$ & $39 \%$ & $53 \%$ & $62 \%$ & $48 \%$ & $46 \%$ & $51 \%$ \\
\hline$\%$ Work location at home & $30 \%$ & $32 \%$ & $23 \%$ & $44 \%$ & $42 \%$ & $34 \%$ \\
\hline $\begin{array}{l}\text { \% Low level of life } \\
\text { satisfaction scale (1-3 points) }\end{array}$ & $20 \%$ & $13 \%$ & $11 \%$ & $10 \%$ & $16 \%$ & $14 \%$ \\
\hline
\end{tabular}

Source: CPSS-Series3 Survey, Statistics Canada, 2020 


\subsection{Reflections}

One major contribution market segmentation analysis like the one carried-out here is the discovery of hidden behavioural patterns and the ability to link statistical methods to the monitoring of outcomes during the COVID-19 pandemic in Canada. A statistical portrait of COVID-19 virus infection fears using marketing segmentation techniques can help federal, regional and local decision makers to better identify universal market segments and tailor segment-suited interventions. Rather than "one size fits all" results, public health programs and activities can be developed for each population cluster and provide tools that can change perceptions and develop more effective responses to tackle positive and negative outcomes in the always-changing COVID-19 confinement environment.

It should be noted that the available public version of the CPSS-Series3 survey, regrettably, did not contain provincial or territorial breakdowns and was limited to individual reporting during the "first" phase of the pandemic (June, 2020). In the "second" and subsequent phases of the pandemic, shifts in the share of segment composition are likely to occur and so it is desirable to produce a larger longitudinal picture. Frequent surveys carried out by Statistics Canada and other data collection agencies are desirable and may yield important information on the common transitions of individuals from one cluster to another.

In this study, five population segments were clearly identified using a combination of principal component and $\mathrm{k}$-means cluster statistical analysis of members of the first four segments (Germophobes, Crowd-Averse, Fearless, Outside "Bubble"-Averse and Nursing Homes-Averse). Regardless of place, circumstance and/or activity, the Germophobes were extremely fearful of contracting the virus while members of the Fearless segment, a polar opposite, underestimated health risks and carried on with their lives with minor preoccupations. Crowd-Averse, Outside "Bubble"-Averse and Nursing Homes-Averse segment members showed differences in terms of the foci of COVID-19 potential infections. A higher level of fear and anxiety of contracting COVID-19 infections can lead to negative outcomes such as mental health deterioration and low personal efficacy (see for instance the work of Zajacova et. al (2020) with CPSS Series 1 data). However, the same fear may also lead to positive outcomes for individuals such as a greater emphasis on personal care and a stricter application of sanitary guidelines and personal security in both public and private spaces.

In light of the present findings, a deeper investigation of behavioural outcomes in each population segment is desirable. In the case of the Germophobe, Outside "Bubble"Averse and Nursing Homes-Averse groups, it is important to know how their perceived virus infection risks balance out with that of their altruistic motivations to take of care of others. The Crowd-Averse segment is exemplary in terms of following the enacted sanitary guidelines. This investigation of outcomes also applies to the Fearless segment as well whose "self-confident" members may be at greater risk of negligence in following the safety guidelines. Given their unique perceptual profiles, public health messages will be more efficient if their messages pay special attention to the particular sociodemographic, residential, employment and psychosocial characteristics of segment members. 


\subsection{References}

Alfaroy, L; Faiaz, E.; Lamersdorfx, N.; and, Saidi, F (2020) Social Interactions in Pandemics: Fear, Altruism, and Reciprocity (2020), NBER Working Paper Series, No. 27134

Grover, R and Vriens, M (2006), A Guide to the Design and Execution of Segmentation Studies, The Handbook of Marketing Research, Sage Publishing.

Kelly, J.R.(2019).Leisure Activities and Interactions, London: Routledge.

Maeng, L. Y. , \& Milad, M. R. (2015 ). Sex differences in anxiety disorders: Interactions between fear, stress, and gonadal hormones. Hormones and Behavior , 76 , $106-117$.

https://doi.org/10.1016/j.yhbeh.2015.04.002

Manderson, L. and Levine, S. (2020) COVID-19, Risk, Fear, and Fall-out, Lenore Manderson \& Susan Levine (2020) COVID-19, Risk, Fear, and Fall-out, Medical Anthropology, 39:5, 367-370, DOI: $10.1080 / 01459740.2020 .1746301$

Punj, G., \& Stewart, D. (1983). Cluster analysis in marketing research: Review and suggestions for application. Journal of Marketing Research, 20, 134- 148.

Salkind, N.J., and Rasmussen, K. (2010) k-Means Cluster Analysis, Encyclopedia of Measurement and Statistics: Sage Publishing

World Health Organization-WHO. (2020) . Mental Health and Psychosocial Considerations During COVID-19 Outbreak; World Health Organization: Genève, Switzerland, 2020.

Zajacova, A.; Jehn, A.; Stackhouse, J.; Choi, K; Denice, P.; Haan, M and Ramos, H. (2020). Mental Health and Economic Concerns from March to May during the COVID-19 Pandemic in Canada, Socarxiv papers: https://osf.io/preprints/socarxiv/76me2 
7.0. Technical Appendix

Chart A-1: Within Class Sum of Squares Variation Ratio for various cluster solutions

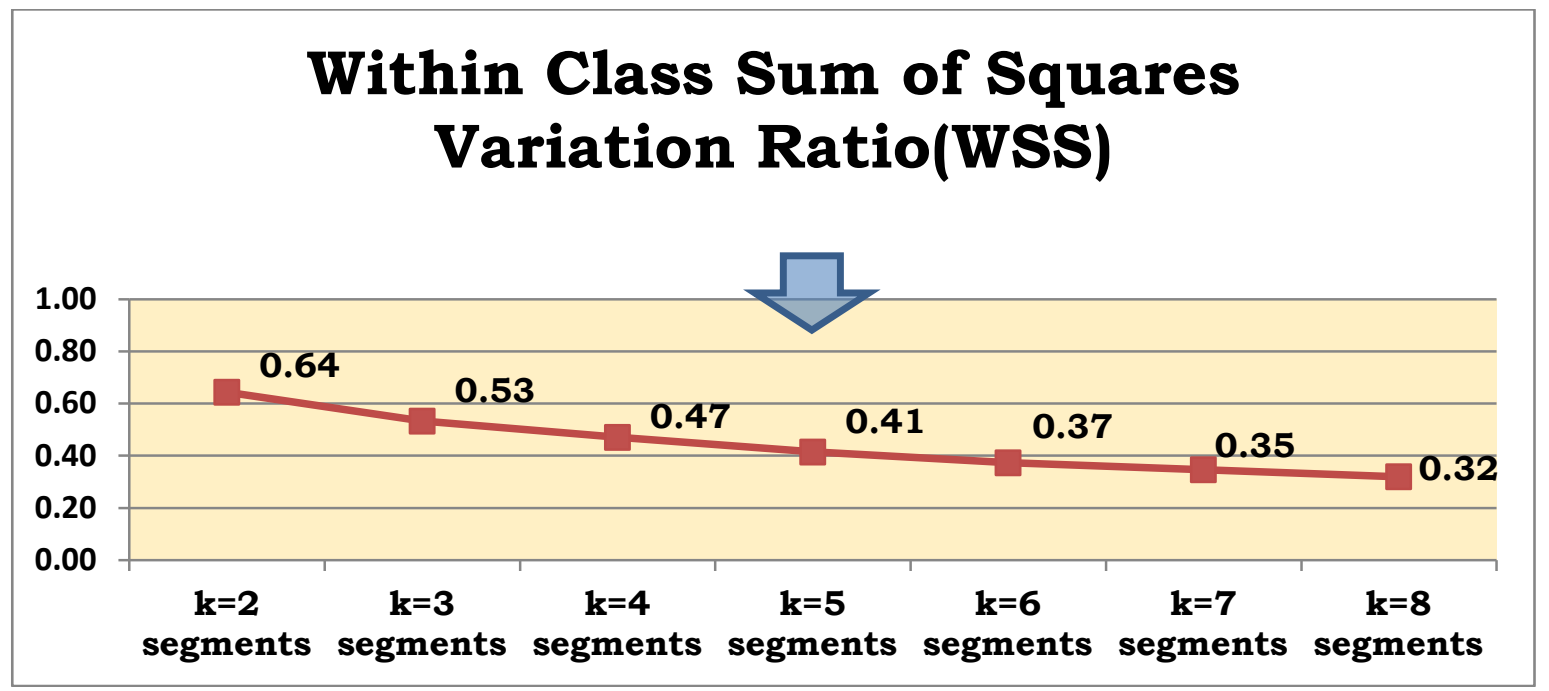

Source: CPSS-Series3 Survey, Statistics Canada, 2020

Table A-2:ANOVA F tests predicting Socio-Demographic, Residential, Employment and Life Satisfaction Characteristics of CPSS-Series 3 survey Respondents

\begin{tabular}{|c|c|c|c|c|c|c|}
\hline ANOVA Results & $\begin{array}{l}\text { Sum of } \\
\text { Squares }\end{array}$ & d.f. & $\begin{array}{l}\text { Mean } \\
\text { Square }\end{array}$ & F Ratio & Sig. & $\begin{array}{l}\mathbf{R} \\
\text { Square }\end{array}$ \\
\hline Age group of respondent & 1160874.1 & 4 & 290218.5 & 151646.4 & 0.00 & 0.03 \\
\hline Sex of respondent & 13751.8 & 4 & 3438.0 & 13846.9 & 0.00 & 0.01 \\
\hline Marital status of respondent & 991282.7 & 4 & 247820.7 & 150411.1 & 0.00 & 0.03 \\
\hline Immigration status & 161594.6 & 4 & 40398.6 & 243459.8 & 0.00 & 0.06 \\
\hline $\begin{array}{l}\text { Respondents highest level of } \\
\text { education ever completed }\end{array}$ & 1377499.6 & 4 & 344374.9 & 92435.9 & 0.00 & \\
\hline $\begin{array}{l}\text { Child under } 18 \text { on June } 15 \text { th, } 2020 \\
\text { resides in dwelling }\end{array}$ & 25778.1 & 4 & 6444.5 & 26481.7 & 0.00 & 0.01 \\
\hline Household size & 109654.0 & 4 & 27413.5 & 31215.5 & 0.00 & 0.01 \\
\hline Rural/Urban indicator & 59539.5 & 4 & 14884.9 & 118216.5 & 0.00 & 0.03 \\
\hline Type of dwelling & 465863.3 & 4 & 116465.8 & 89075.7 & 0.00 & 0.02 \\
\hline Telework Status & 203879.7 & 4 & 50969.9 & 62294.9 & 0.00 & 0.02 \\
\hline Employment status & 31289.4 & 4 & 7822.3 & 28344.2 & 0.00 & 0.01 \\
\hline Life satisfaction level & 1306428.3 & 4 & 326607.1 & 74334.2 & 0.00 & 0.02 \\
\hline
\end{tabular}

